\title{
Effects of TRAIL and taurolidine on apoptosis and proliferation in human rhabdomyosarcoma, leiomyosarcoma and epithelioid cell sarcoma
}

\author{
C. KARLISCH ${ }^{1 *}$, K. HARATI ${ }^{2 *}$, A.M.CHROMIK ${ }^{3}$, D. BULUT ${ }^{4}$, L. KLEIN-HITPASS ${ }^{5}$,

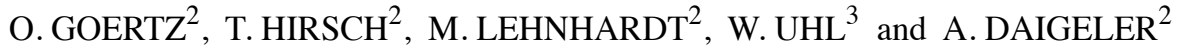 \\ ${ }^{1}$ Department of Gynecology and Obstetrics, Marienhospital Witten, Ruhr-University, D-58452 Witten; \\ ${ }^{2}$ Department of Plastic Surgery, Burn Center, Hand Center, Sarcoma Reference Center, BG-University Hospital \\ Bergmannsheil, D-44789 Bochum; Departments of ${ }^{3}$ General and Visceral Surgery and ${ }^{4}$ Medicine II, \\ St. Josef Hospital, Ruhr-University, D-44791 Bochum; ${ }^{5}$ Institute for Cell Biology (Tumor Research), \\ University of Duisburg-Essen, D-45122 Essen, Germany
}

Received October 25, 2012; Accepted December 7, 2012

DOI: $10.3892 /$ ijo.2013.1772

\begin{abstract}
Soft tissue sarcomas (STS) are a heterogeneous group of malignant tumours representing $1 \%$ of all malignancies in adults. Therapy for STS should be individualised and multimodal, but complete surgical resection with clear margins remains the mainstay of therapy. Disseminated soft tissue sarcoma still represents a therapeutic dilemma. Commonly used chemotherapeutic agents such as doxorubicin and ifosfamide have proven to be effective in fewer than $30 \%$ in these cases. Therefore, we tested the apoptotic and anti-proliferative in vitro effects of TNF-related apoptosis-inducing ligand (TRAIL) and taurolidine (TRD) on rhabdomyosarcoma (A-204), leiomyosarcoma (SK-LMS-1) and epithelioid cell sarcoma (VA-ES-BJ) cell lines. Viability, apoptosis and necrosis were quantified by FACS analysis (propidium iodide/Annexin V staining). Gene expression was analysed by DNA microarrays and the results validated for selected genes by rtPCR. Protein level changes were documented by western blot analysis. Cell proliferation was analysed by BrdU ELISA assay. The single substances TRAIL and TRD significantly induced apoptotic cell death and decreased proliferation in rhabdomyosarcoma and epithelioid cell sarcoma cells. The combined use of TRAIL and TRD resulted in a synergistic apoptotic effect
\end{abstract}

Correspondence to: Dr Kamran Harati, Department of Plastic Surgery, BG-University Hospital Bergmannsheil, Buerkle-de-laCamp-Platz 1, D-44789 Bochum, Germany

E-mail:kamran.harati@t-online.de

${ }^{*}$ Contributed equally

Key words: soft tissue sarcoma, rhabdomyosarcoma, leiomyosarcoma, epithelioid cell sarcoma, taurolidine, TNF-related apoptosis-inducing ligand, HSPA1A/B, NF-кBIA, PPP1R15A, GADD45A, FYN, PPM1D, JUN, WEE1, FADD in all three cell lines, especially in rhabdomyosarcoma cells leaving $18 \%$ viable cells after $48 \mathrm{~h}$ of incubation $(\mathrm{p}<0.05)$. Analysis of the differentially regulated genes revealed that TRD and TRAIL influence apoptotic pathways, including the TNF-receptor associated and the mitochondrial pathway. Microarray analysis revealed remarkable expression changes in a variety of genes, which are involved in different apoptotic pathways and cross talk to other pathways at multiple levels. This in vitro study demonstrates that TRAIL and TRD synergise in inducing apoptosis and inhibiting proliferation in different human STS cell lines. Effects on gene expression differ relevantly in the sarcoma entities. These results provide experimental support for in vivo trials assessing the effect of TRAIL and TRD in STS and sustain the approach of individualized therapy.

\section{Introduction}

Soft tissue sarcomas (STS) are a heterogeneous group of malignant neoplasms. They represent $15 \%$ of all malignancies in children and $1 \%$ in adults (1). The therapy of choice involves surgical resection with a wide margin of healthy tissue, usually followed by radiation treatment in order to decrease local recurrence $(2,3)$. Unfortunately, about $50 \%$ of all patients develop distant metastases and are ineligible for surgical treatment $(4,5)$. In cases of advanced metastatic disease the median survival time from the time of diagnosis with and without chemotherapy treatment is less than 12 months $(6,7)$. Few agents such as doxorubicin, ifosfamide and dacarbazine have proven to be effective in the therapy of soft tissue sarcomas (2). However, the results of these treatments are poor and often exhibit no significant improvements in overall survival (8). Doxorubicin, which has been the most frequently used chemotherapeutic agent in the treatment of soft tissue sarcomas, demonstrates response rates of 20 to $30 \%$ in disseminated disease $(9,10)$. The combination of doxorubicin with ifosfamide is more effective, exhibiting slightly higher response rates than doxorubicin alone, but is associated with 
severe short- and long-term toxicities, including bone marrow suppression $(11,12)$. To date, most large trials have not distinguished between histological subtypes of soft tissue sarcomas. One example of such an early trial is the EORTC 62771 trial which was conducted in 1994 and involved 317 patients with several histological types of sarcomas (malignant fibrous histiocytoma, synovial sarcoma, liposarcoma and leiomyosarcoma) (13). Local recurrence was reduced in the chemotherapy arm, but there was no significant benefit in overall survival. The Sarcoma Meta-Analysis Collaboration in 1997 published a quantitative meta-analysis of 1,568 patients with localized resectable soft tissue sarcomas and reported that doxorubicin-based adjuvant chemotherapy significantly improved the time to local and distant recurrence and overall recurrence-free survival. However, there was no significant overall survival benefit at 10 years (14). Unfortunately, most of the large meta-analyses did not differentiate between histological subtypes because of the overall rarity of soft tissue sarcomas. However, differentiation is an important prognostic factor because the soft tissue sarcoma subtypes are differentially sensitive to several agents (2). In recent phase II trials, paclitaxel has proven to be effective in the treatment of angiosarcomas, whereas trabectedin has demonstrated promising activity in leiomyosarcomas and liposarcomas $(2,15,16)$.

Within the scope of this trial, we investigated the effects of TRAIL and taurolidine on three different STS cell lines. Two common subtypes of soft tissue sarcomas, rhabdomyosarcoma (A-204) in children and leiomyosarcoma (SK-LMS-1) in adults (1), and epithelioid cell sarcoma (VA-ES-BJ), which is a rare subtype affecting mostly young patients and has a poor long-term prognosis (17), were examined.

TRAIL and taurolidine are promising combination partners that exhibit synergistic apoptotic effects on a wide range of malignant cells in vitro, including carcinoma cells of the oesophagus, pancreas, colon and liver (18-20) as well as fibrosarcoma (21).

Since the discovery of TRAIL, a member of the TNF-superfamily, its apoptosis-inducing effects were documented in several types of malignant cells (22-25). TRAIL binds to its receptors DR4 and DR5 (death receptor 4 and 5) resulting in receptor oligomerization and recruitment of FAS-associated protein with death domain (FADD) and caspase 8, forming a functional death-inducing signalling complex (DISC). Subsequently, DISC leads to the activation of the extrinsic pathway of apoptosis via caspase 8 (26-28). However, associations between TRAIL and the intrinsic mitochondrial pathway have been also described (20). In this pathway, formation of the apoptosome is a key regulatory point following the release of mitochondrial cytochrome $c$ and thus leading to apoptosis (29).

Taurolidine (TRD) is an antiseptic agent derived from the amino acid taurine. It has been used to treat peritonitis and catheter-related infections (18). Recently, TRD was used effectively to treat malignant diseases (30-33). In a variety of malignant cell lines including carcinomas of the gastrointestinal tract as well as glioblastoma, fibrosarcoma, prostate and melanoma cancer cell lines, TRD caused the inhibition of proliferation $(31,34$ 36), the inhibition of angiogenesis (30) and the induction of cell death (20,30-32,37-39). The precise mechanism of action is still not clear, but translational inhibition (35) and several pathways of programmed cell death (38) have been implicated. Some groups suggest that the extrinsic pathway $(19,20,31,39,40)$ is involved, whereas others report involvement of the intrinsic pathway (37,41). Furthermore, first clinical use of TRD was associated with remarkable low toxicity which could be a decided advantage over established chemotherapeutic agents $(30,42)$. TRD was well tolerated after intravenous application in patients with advanced melanoma or glioblastoma $(43,44)$.

Recent in vitro studies have revealed that the combination of TRAIL and TRD resulted in sustained cell death, which was superior to single application of TRAIL or TRD. This is despite the use of lower concentrations of both substances in the combination trials $(19,20,40)$. Experimental findings have demonstrated that combined treatment with taurolidine reduces the potential toxic side-effects of TRAIL, not only by reducing the required optimal dose of TRAIL but also by modulating TRAIL's effector pathways without affecting its antitumour efficacy (20). Inspired by these results, we examined the effects of TRAIL and TRD on rhabdomyosarcoma (A-204), leiomyosarcoma (SK-LMS-1) and epithelioid cell sarcoma (VA-ES-BJ) cells.

\section{Materials and methods}

Cell lines and cell culture. Three different cell lines were used for this study. The human rhabdomyosarcoma cell line A-204 was purchased from DSMZ (Braunschweig, Germany, DSMZ no. ACC 250) and cultivated in McCoy's 5A with glutamine and $10 \%$ fetal bovine serum (FBS). Human leiomyosarcoma cells, SK-LMS-1, were purchased from ATCC (Manassas, USA) and maintained in MEM with Earle's Salts supplemented with $10 \%$ FBS, $1 \%$ non-essential amino acids, $1 \mathrm{mM}$ sodium pyruvate and $2 \mathrm{mM}$ L-glutamine. The human epithelioid sarcoma cell line VA-ES-BJ also was purchased from DSMZ (DSMZ no. ACC 328) and was cultured in Dulbecco's MEM with sodium pyruvate, supplemented with $20 \%$ FBS, $1 \%$ non-essential amino acids and $2 \mathrm{mM}$ L-glutamine. All culture media were supplemented with $100 \mathrm{U} / \mathrm{ml}$ penicillin and $100 \mu \mathrm{g} / \mathrm{ml}$ streptomycin. The cells were grown to a sub-confluent monolayer and maintained at $37^{\circ} \mathrm{C}$ and $5 \% \mathrm{CO}_{2}$ in a humidified atmosphere.

Reagents. TRD (Taurolin ${ }^{\circledR} 2 \%$, Boehringer Ingelheim, Ingelheim, Germany) containing 5\% Povidon was used as supplied by the manufacturer. A 5\% Povidon solution (K16 Povidon, generously provided by Geistlich Pharma AG, Wolhusen, Switzerland) was applied in equal volume and served as a control for the TRD group. Recombinant human TRAIL/ Apo2L (Bender MedSystems GmbH, Vienna, Austria) was dissolved in distilled water according to the manufacturer's instructions. Distilled water served as a control for TRAIL and was applied in equal volume.

Dose-finding study and application of reagents. To determine the most effective single concentrations and the time dependency of the effects, cells were incubated with various concentrations of TRAIL (50, 100, 250 and $500 \mathrm{ng} / \mathrm{ml})$, TRD (50, 100, 250 and $500 \mu \mathrm{mol} / \mathrm{l}$ ) and the respective controls (distilled water or Povidon) for 2, 6, 12, 24 and $48 \mathrm{~h}$. All experiments were repeated with three consecutive cell passages. All cell lines showed highest apoptotic response to $250 \mathrm{ng} / \mathrm{ml}$ TRAIL and $250 \mu \mathrm{mol} / 1$ TRD as single substances. These most effective single concentrations of TRD and TRAIL were then used as single substances and in combination to identify a possibly synergistic effect. We chose 2, 6, 12, 24 and 48-h time points. 
Flow cytometry analysis. After the defined incubation time, the supernatant with floating cells was collected and the adherent cells were harvested by trypsinisation. These cells were centrifuged and subsequently resolved with Binding Buffer (Bender MedSystems $\mathrm{GmbH}$ ) to an absolute cell count of $1 \times 10^{5}$. Next, the cells were incubated with Annexin V-FITC (BD Biosciences, Heidelberg, Germany) and propidium iodide (PI, Bender MedSystems $\mathrm{GmbH}$ ) following the manufacturer's instructions. Cells were analysed using a FACS flow cytometer (BD FACSCalibur, BD Biosciences). Cells $(20,000)$ were counted for each measurement. Dot plots and histograms were analysed by CellQuest Pro Software (BD Biosciences). Annexin V binds phosphatidylserine on the outer membranes of cells, and phosphatidylserine becomes exposed on the surfaces of apoptotic cells. Thus, the Annexin V-positive cells were considered apoptotic. PI is an intercalating agent that cannot permeate through the cell membranes of viable or early apoptotic cells. Therefore, PI stains only the DNA of necrotic or very late apoptotic cells. In this study, Annexin V-and PI-positive cells were termed necrotic. Annexin V-and PI-negative cells were counted as viable.

Cell morphology. Morphology of cultured cells was observed and documented using a phase contrast microscope (Zeiss Axiovert 25, Carl Zeiss, Göttingen, Germany).

TUNEL assay. To stain apoptotic cells, we used terminal deoxynucleotidyl transferase-mediated dUTP nick end-labelling consistent with the manufacturer's protocol (In Situ Cell Death Detection Kit, Fluorescein, Roche Applied Science, Mannheim, Germany). Cells were incubated with the appropriate reagents (TRD/TRAIL) for $12 \mathrm{~h}$.

Proliferation assay. To evaluate the proliferation of the cells, we used a colorimetric cell proliferation BrdU-ELISA (Roche Applied Science) according to the manufacturer's instructions. An ELISA-Reader (Sunrise ${ }^{\mathrm{TM}}$, Tecan Trading AG, Männedorf, Switzerland) was used to detect the amount of newly synthesised DNA. We plated 10,000 cells per well in a 96-well plate. The incubation time was $6 \mathrm{~h}$.

Statistical analysis. SPSS Version 17.0 for Windows was used for statistical analysis. The results of FACS analysis for percentages of viable, apoptotic and necrotic cells are given as the means \pm SEM of three independent experiments with consecutive passages. In this study, comparisons between experimental groups were performed using one-way analysis of variance (one-way ANOVA) and a post hoc test (Tukey's) over all time points and at singular time points. P-values $\leq 0.05$ were considered statistically significant and indicated in the figures as follows: ${ }^{* * *} \mathrm{p} \leq 0.001,{ }^{* *} \mathrm{p} \leq 0.005$ and ${ }^{*} \mathrm{p} \leq 0.05$.

Oligonucleotide microarray analysis. To identify the changes in gene expression levels caused by the treatment with TRAIL and TRD, total-RNA was purified from the cells after incubation with the appropriate agent for $6 \mathrm{~h}$ using a RNeasy kit from Qiagen (Hilden, Germany) as specified by the manufacturer. RNA integrity was assessed using an Agilent 2100 Bioanalyzer (Agilent Technologies, Santa Clara, CA, USA). For microarray analyses, we applied the methods previously described by Daigeler et al (40). We used the Affymetrix GeneChip platform, employing a standard protocol for sample preparation and microarray hybridisation. A one-way ANOVA model followed by Tukey's HSD (Honestly Significant Difference)-test was used to verify the hypothesis that there were no differences in expression between the drug-treated group and the control group. The multiplicity correction was performed using Benjamini and Hochberg procedure to control the false discovery rate (FDR) at $0.05 \%$. In a pair-wise comparison of the differentially expressed genes between the control and the drug-treated cells identified by the ANOVA analyses, a subset of genes was identified that displayed a conjoint regulation in the treated cells. Genes were placed in this latter group if they exhibited a mean $\geq 2$-fold increase or decrease compared to the control cells. This subset of genes was subjected to the GeneTrail (45) software to identify any over-representation of genes associated with the regulatory pathways that are represented in the Kyoto Encyclopaedia of Genes and Genomes (KEGG) and TRANSPATH databases. Microarray data are deposited in the GEO public database (accession no. GSE36572). These methods fulfilled the MIAME criteria (http://www.mged.org/miame).

Real-time PCR for microarray data validation. Microarray data validation was performed for selected candidate genes (BAG5, EGFR, FADD, FYN, GADD45A, HSPA1B/HSP70, NEU1, PPM1D, PPP1R15A/GADD34, PPP1R3D, SIAH1, WEE1). RNA isolation was performed from cells harvested after $6 \mathrm{~h}$ of treatment. Total-RNA $(2 \mu \mathrm{g})$ was reverse transcribed using the High Capacity cDNA Archive kit (Applied Biosystems, Carslbad, CA, USA). Real-time PCR was performed with a 7900 HT SDS system (Applied Biosystems) in a $20 \mu \mathrm{l}$ reaction volume containing $1 \mathrm{X}$ Master Mix, $1 \mu \mathrm{l}$ assay and cDNA equivalent to $2 \mathrm{ng}$ total-RNA. All reagents and real-time PCR assays (BAG5 Hs00191644_m1, EGFR Hs01076092_m1, FADD Hs00538709_m1, FYN Hs00941604_ m1, GADD45A Hs00169255_m1, HSPA1B Hs01040501_sH, NEU1 Hs00166421_m1, PPM1D Hs01013293_m1, PPP1R15A Hs00169585_m1, PPP1R3D Hs00901540_s1, SIAH1 Hs00361785_m1, WEE1 Hs01119388_m1) were purchased from Applied Biosystems. Reactions were performed in duplicate and analysed by the $\Delta \Delta \mathrm{Ct}$ method. Human GAPD was used for normalisation.

Western blot analysis. Western blot analyses were performed to validate the effects of alterations in gene expression on protein levels using an SDS-PAGE gel and the following antibodies (except BAG5, which was purchased from Abcam PLC, Cambridge, UK); all other antibodies were purchased from Santa Cruz Biotechnology Inc. (Heidelberg, Germany): BAG5 (mouse, ab56738), EGFR (rabbit, 1005), FADD (rabbit, H-181), GADD34/PPP1R15A (rabbit, S-20), GADD45 $\alpha$ (rabbit, H-165), HSP70 (mouse, C92F3A-5) and Weel (rabbit, C-20). Western blot analyses were not performed for PPPM1D, FYN and PPP1R3D because functional antibodies were not available. Total protein was purified from the cells after incubation with the appropriate substances for $8 \mathrm{~h}$. Floating cells were collected together with the supernatant; adherent cells were harvested using a cell scraper and added to the solution. Cells were gathered by centrifugation. After removal of the supernatant, pellets were incubated with $100 \mu$ l Cell Culture Lysis Reagent (Promega Corporation, Mannheim, Germany) each for $1 \mathrm{~h}$ on 

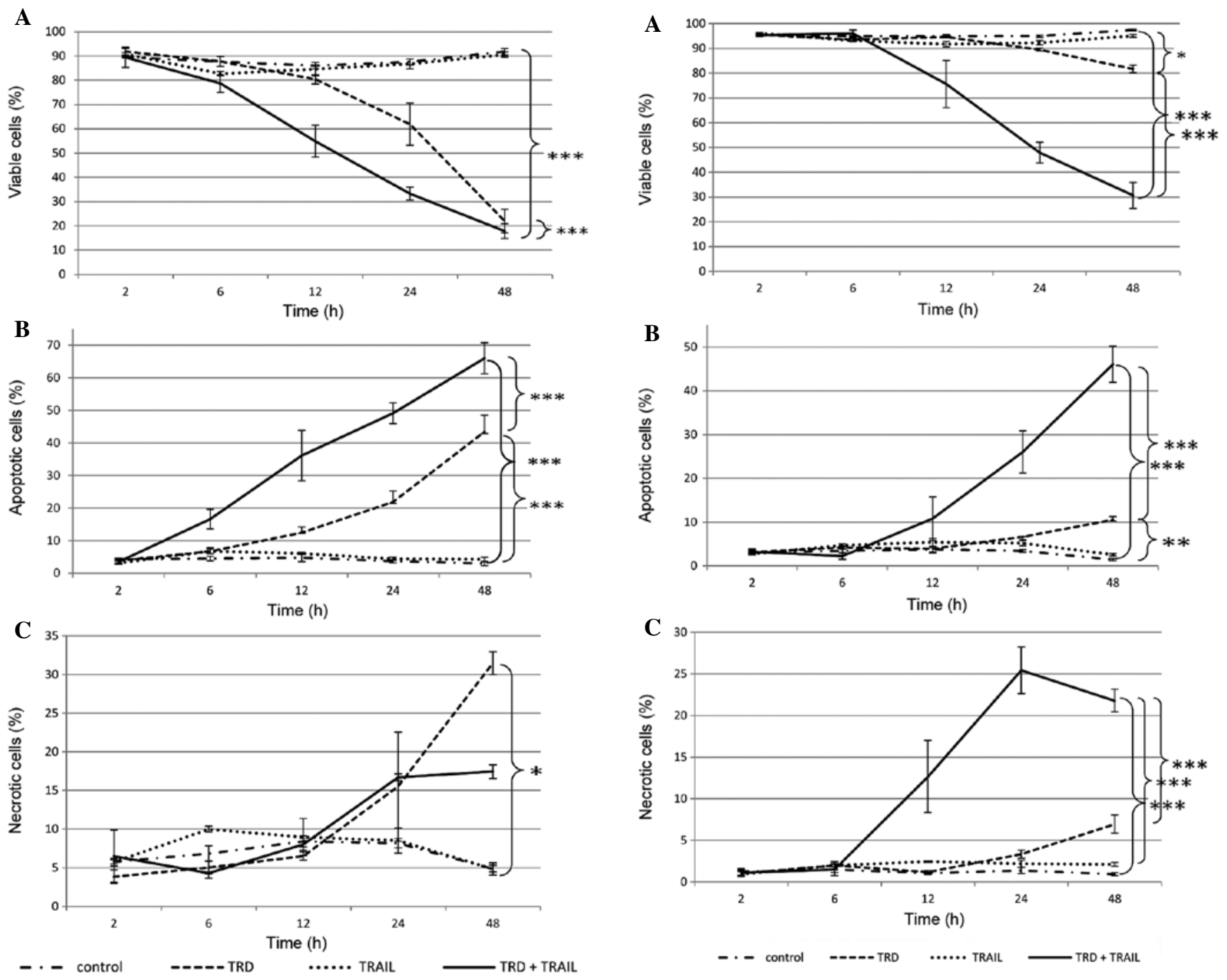

Figure 1. Effects of TRAIL, TRD and combination of both reagents on rhabdomyosarcoma (A-204) cells. A-204 cells were incubated for 2-48 h with TRAIL, TRD and combination of both reagents. The percentages of (A) viable, (B) apoptotic and (C) necrotic cells were determined using fluorescence activated cell sorting (FACS) analysis for Annexin V-FITC and propidium iodide. The values indicate the means \pm SD of three independent experiments and consecutive passages. Significantly different at ${ }^{* * *} \mathrm{p} \leq 0.001,{ }^{* *} \mathrm{p} \leq 0.005,{ }^{*} \mathrm{p}<0.05$; one-way ANOVA.

ice. The cell remnants were then separated by centrifugation, and the supernatant containing the purified protein was frozen at $-80^{\circ} \mathrm{C}$ until further use.

\section{Results}

The combination of TRAIL and TRD amplifies apoptotic effects in A-204 human rhabdomyosarcoma and VA-ES-BJ human epithelioid sarcoma cells. Single application of TRD induced significantly apoptotic and necrotic cell death in A-204 human rhabdomyosarcoma cells. Viable cells were decreased to $22.0 \%$ after $48 \mathrm{~h}$ of incubation compared to $91.9 \%$ in the control and $90.6 \%$ in the TRAIL group $(\mathrm{p}<0.001)$ (Fig. 1). Addition of TRAIL promoted the apoptotic influence of TRD in rhabdomyosarcoma cells. The combined treatment of TRD and TRAIL resulted in a marked increase in cells undergoing

apoptosis over all time points ( $\mathrm{p} \leq 0.001)$. After $6 \mathrm{~h}$ of incubation first apoptotic effects were seen. The combination with TRAIL and TRD exhibited highest apoptosis rates after $48 \mathrm{~h}$ with $66.1 \%$ apoptotic cells ( $3.0 \%$ in control group, $\mathrm{p} \leq 0.001)$. Thus, combination treatment was most effective in reducing cell viability with $17.9 \%$ remaining viable cells after $48 \mathrm{~h}$ (vs. $91.9 \%$ in the control group, p<0.001) (Fig. 1A).

The viability of the VA-ES-BJ human epithelioid sarcoma cells was moderately but significantly reduced by single treatment with TRD (Fig. 2). A total of $81.8 \%$ of the cells was detected as viable after $48 \mathrm{~h}$ treatment with TRD (vs. $97.5 \%$ in the control group, $p=0.015$ ). Single application of TRAIL had no significant effect on cell viability. The combined treatment with TRAIL and TRD led to a significant increased apoptotic cell death after $12 \mathrm{~h}$. The population of viable cells 

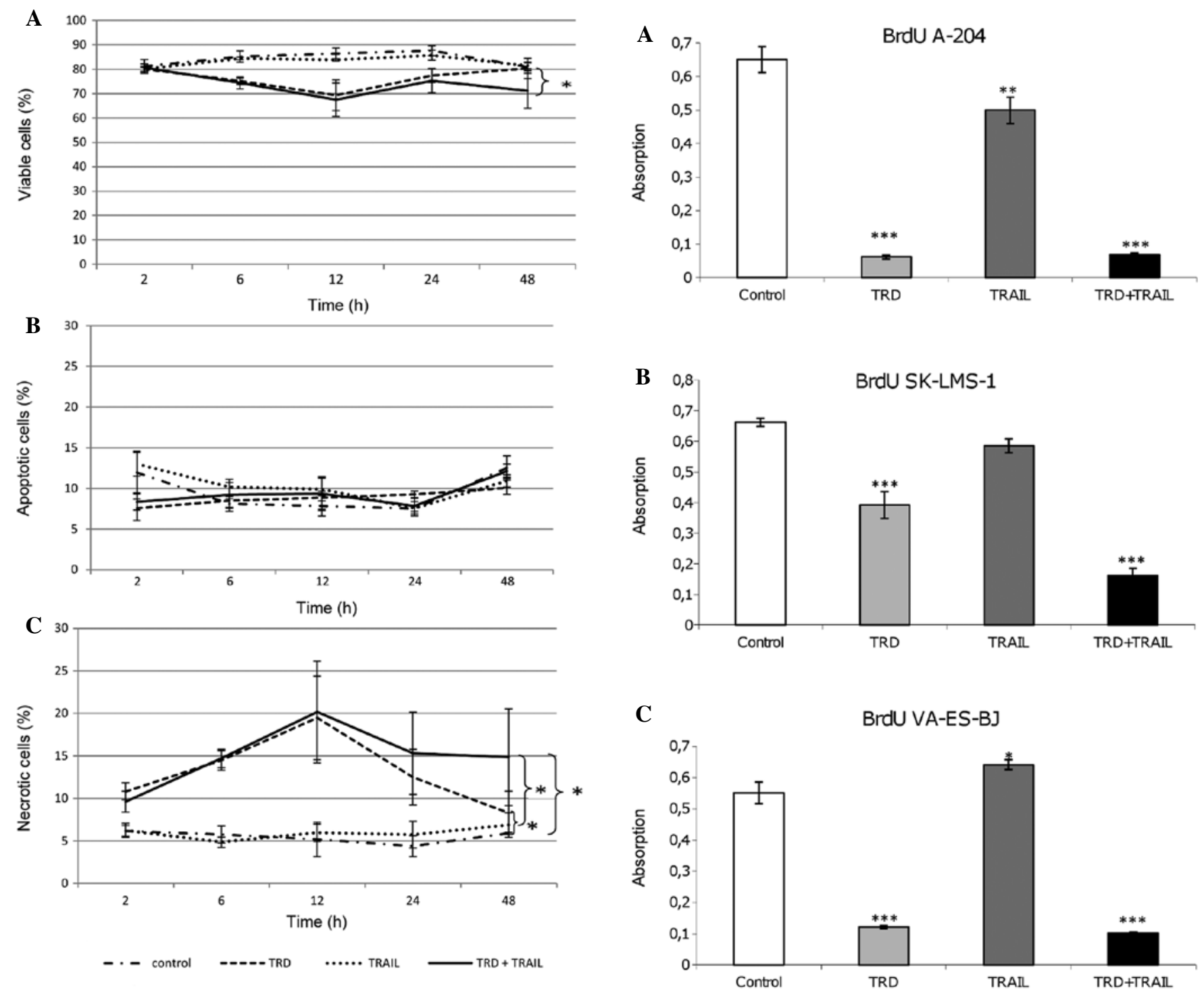

Figure 3. Effects of TRAIL, TRD and combination of both reagents on leiomyosarcoma (SK-LMS-1) cells. SK-LMS-1 cells were incubated for 2-48 h with TRAIL, TRD and combination of both reagents. The percentages of (A) viable, (B) apoptotic and (C) necrotic cells were determined using fluorescence activated cell sorting (FACS) analysis for Annexin V-FITC and propidium iodide. The values indicate the means \pm SD of three independent experiments and consecutive passages. Significantly different at ${ }^{* * *} \mathrm{p} \leq 0.001,{ }^{* *} \mathrm{p} \leq 0.005$, " $\mathrm{p}<0.05$; one-way ANOVA.

Figure 4. Bromodeoxyuridine (BrdU) proliferation assay. The effects of the indicated compounds on proliferation in (A) A-204, (B) SK-LMS-1 and (C) VA-ES-BJ cells were measured by BrdU cell proliferation assay. The assay was performed following $6 \mathrm{~h}$ of incubation with sodium pyruvate (control), $250 \mu \mathrm{mol} / 1 \mathrm{TRD}, 250 \mathrm{ng} / \mathrm{ml}$ TRAIL or with a combination of TRD and TRAIL. Data are presented as the mean \pm SD of 8 measurements. ANOVA was used to demonstrate statistical significance between the different categories with a Tukey's multiple comparison post hoc test. Significantly different at $\left.{ }^{* * *} \mathrm{p} \leq 0.001,{ }^{* *} \mathrm{p} \leq 0.005,{ }^{*} \mathrm{p}<0.05 ; \mathrm{ns}, \mathrm{p}>0.05\right)$. The indicators of significance refer to the difference between the treatment groups and the control series.

was reduced to $30.7 \%$ after $48 \mathrm{~h}$ of incubation whereas $97.5 \%$ were left viable in the control group $(\mathrm{p}<0.001)$. Apoptosis also peaked at this time point, reaching a maximum of $46.1 \%$ in the combination group compared to only $1.5 \%$ in the control group $(\mathrm{p}<0.001)$ (Fig. 2A).

Neither single application nor combination treatment with TRAIL and TRD affected viability of SK-LMS-1 leiomyosarcoma cells significantly. The effects when treating SK-LMS-1 leiomyosarcoma cells with TRD and TRAIL were only moderate (Fig. 3). The combined application of TRAIL and TRD led to a slight decrease of viable cells to $67,5 \%$ after $12 \mathrm{~h}$ (vs. $86.5 \%$ in the control group, $\mathrm{p}=0.088$ ). Single application of TRD had a similar effect on SK-LMS-1 cells $(69.4 \%$ viable

cells after $12 \mathrm{~h}$ ). Neither single application nor combination treatment with TRAIL and TRD had a significant influence on apoptosis.

TRD significantly inhibited proliferation of A-204 human rhabdomyosarcoma, VA-ES-BJ human epithelioid sarcoma and SK-LMS-1 leiomyosarcoma cells. TRD was able to inhibit cell proliferation in all examined cell lines $(\mathrm{p}<0.001)$ as indicated by the BrdU-Assay (Fig. 4). In SK-LMS-1 cells, combination with TRAIL resulted in a stronger effect compared to incubation with TRD alone $(\mathrm{p}<0.001)$. For the other cell lines, combination therapy did not increase the inhibition of proliferation. Administration of TRAIL as a single 
A

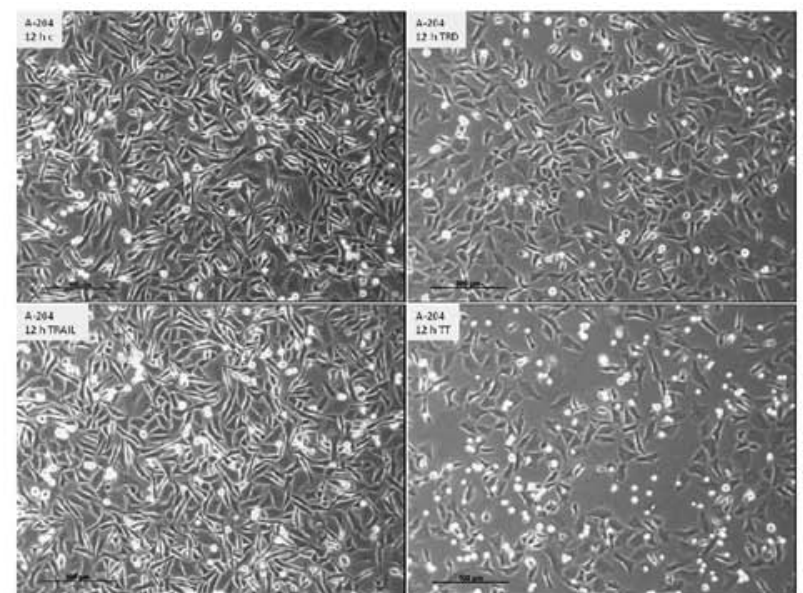

B

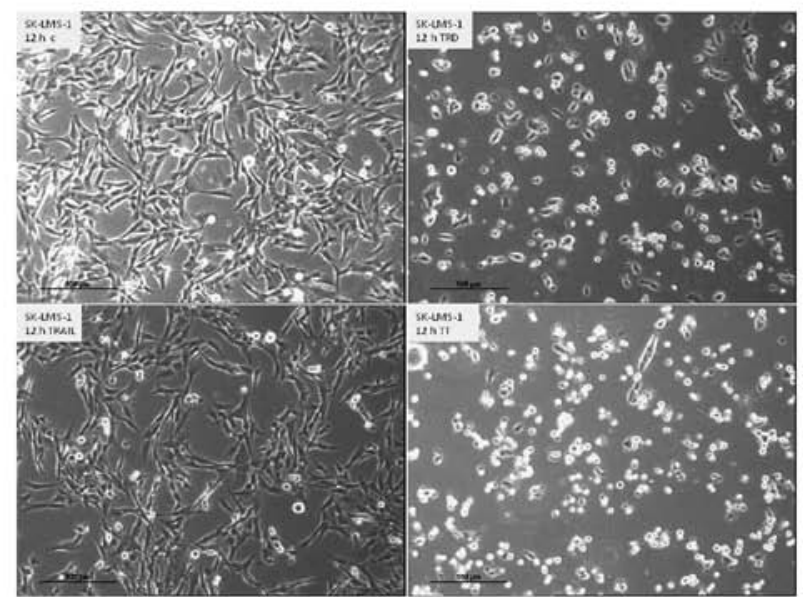

C

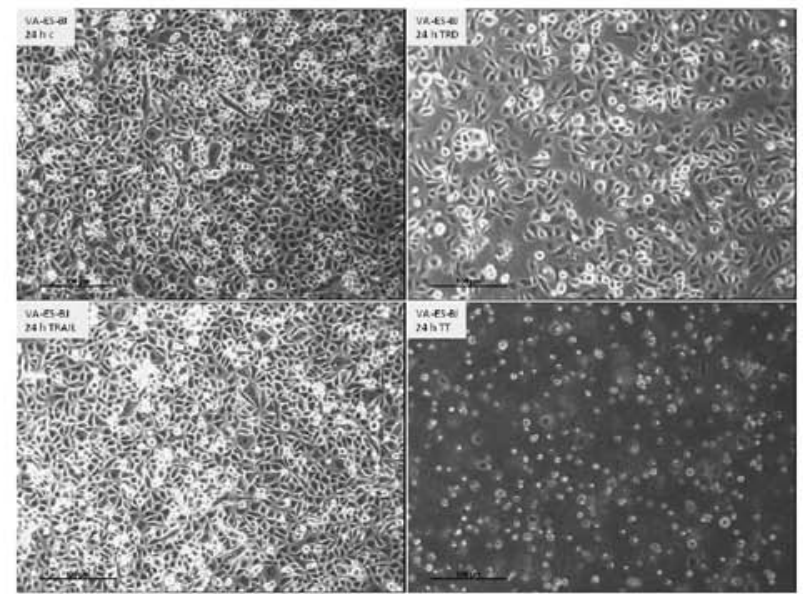

Figure 5. Morphological changes after treatment. Representative microscopic photographs showing morphological changes in (A) A-204, (B) SK-LMS-1 and (C) VA-ES-BJ cells induced by TRD, TRAIL and combination of both after 12 and $24 \mathrm{~h}$, respectively.

agent reduced proliferation significantly only in A-204 cells. Strikingly, proliferation was increased in VA-ES-BJ cells after single application of TRAIL.

The addition of TRD induced morphological changes and cell detachment. As demonstrated in Fig. 5, addition of TRD resulted in morphological changes in all cell lines. TRD led to shrinkage of cells and dissolution of confluent cells groups. Longer incubation with TRD resulted in marked cell detachment.

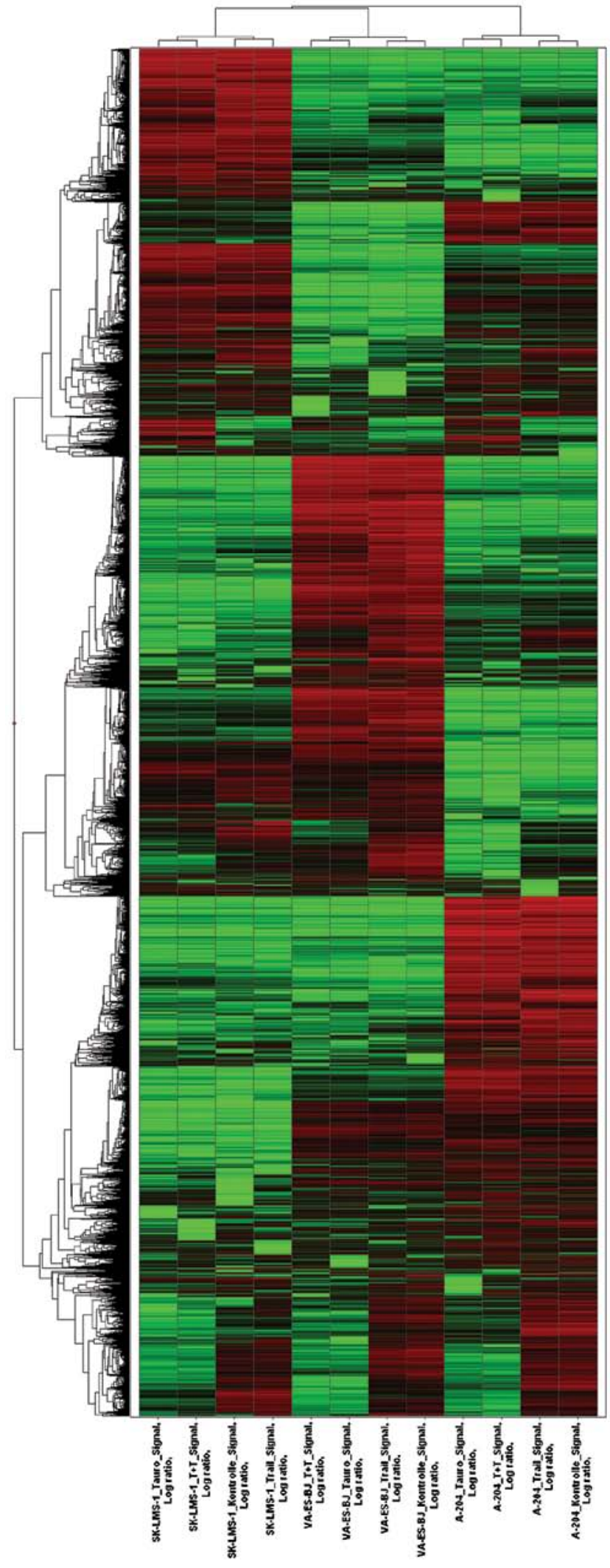

Figure 6. Hierarchical clustering: overall gene expression pattern of reliably measured probesets (24797). Horizontal rows represent individual probe sets/genes; vertical columns represent individual samples. Kontrolle, control; Tauro, TRD; Trail, TRAIL; T+T, combination treatment. Color scale: black, mean (indicates unchanged expression), brightest green, $0,25 \mathrm{x}$ mean (indicates expression level below mean), brightest red, $4 \mathrm{x}$ mean (indicates higher expression level than mean). The dendogram at the top of the matrix indicates the degree of similarity between examined groups; the dendogram at the left side indicates the degree of similarity among the selected genes according to their expression patterns. 
A

GADD45A

A-204

$25 \mathrm{kDa}$

$20 \mathrm{kDa}$

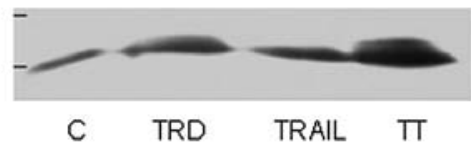

B HSPA1B

SK-LMS-1
VA-ES-BJ

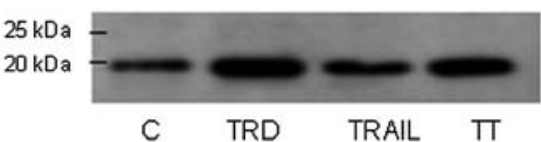

VA-ES-BJ

$75 \mathrm{kDa}$

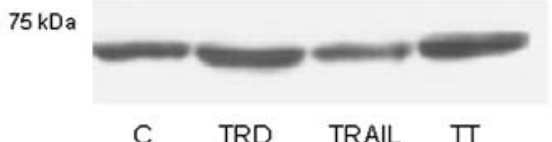

C PPP1R15A

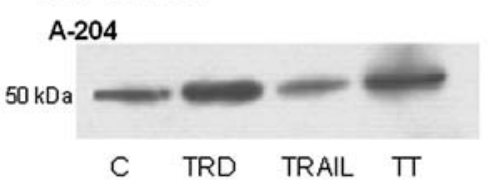

D WEE1

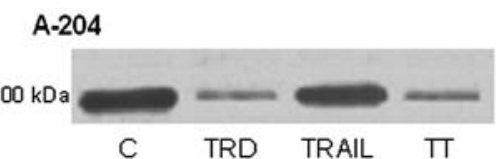

SK-LMS-1

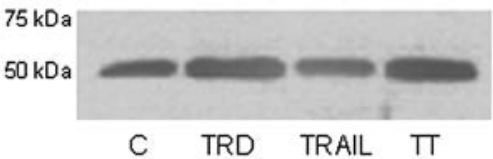

SK-LMS-1

$100 \mathrm{kDa}$

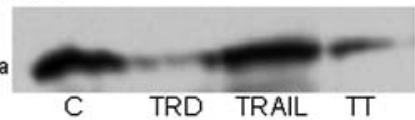

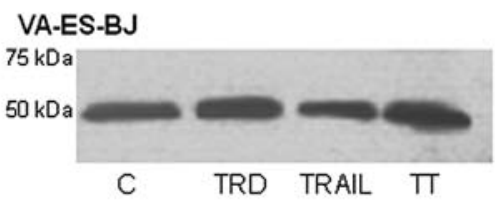

VA-ES-BJ

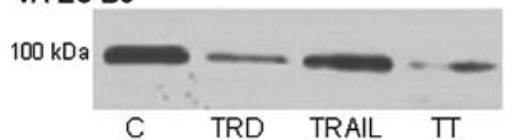

Figure 7. Selected western blot analysis results for candidate proteins. Protein isolation was performed after an incubation time of $8 \mathrm{~h}$ with the respective substances. Antibodies used: GADD34/PPP1R15A (rabbit, S-20), GADD45 $\alpha$ (rabbit, H-165), HSP70 (mouse, C92F3A-5) and Wee1 (rabbit, C-20). C, control; TRD, 250 $\mu$ mol/1 taurolidine; TRAIL, $250 \mathrm{ng} / \mathrm{ml}$ TRAIL; TT, $250 \mu \mathrm{mol} / 1 \mathrm{TRD}$ and $250 \mathrm{ng} / \mathrm{ml}$ TRAIL.

Table I. Number of altered genes with at least a $\geq 2$-fold change in gene expression.

\begin{tabular}{lccccc}
\hline & TRD vs. control & TRAIL vs. control & TT vs. control & TT vs. TRD & TT vs. TRAIL \\
\hline A-204 & 128 & 10 & 113 & 19 & 125 \\
SK-LMS-1 & 116 & 22 & 122 & 2 & 118 \\
VA-ES-BJ & 102 & 35 & 117 & 7 & 97 \\
All three cell lines & 56 & 3 & 53 & 1 & 49 \\
\hline
\end{tabular}

TT, TRAIL and TRD.

Microarray analysis revealed differential gene expression patterns in all examined cell lines after the treatment with TRAIL and TRD. With respect to the overall gene expression patterns, there were differences between the individual cell lines (Fig. 6). In our gene expression study, we focused on apoptosis-related genes. For all three cell lines, we tested 621 probe sets as previously described by Daigeler et al $(20,40)$, which corresponded to 349 genes. TRAIL caused only a few differences in the expression of the analysed genes compared to the control, whereas TRD alone and in combination with TRAIL led to expression changes in a wide range of apoptosis-related genes. The number of altered genes with at least $a \geq 2$-fold change is shown in Table I.

Additional evaluations with real-time PCR for selected candidate genes yielded consistent results regarding changes in expression of several genes. A consistent increase of expression in all three cell lines was observed after TRAIL and TRD treatment for GADD45A (growth arrest and DNA damage A),
PPP1R15A (protein phosphatase 1, regulatory subunit 15A) and HSPA1B (heat shock $70 \mathrm{kDa}$ protein 1B) (Table II). Further, microarray analysis revealed a downregulation of Weel (protein kinase wee1), FADD (Fas-associated protein with death domain), Fyn (proto-oncogene tyrosine-protein kinase Fyn) and PPM1D (protein phosphatase 1D) in several treatment groups.

Western blot analyses demonstrated consistent results for gene expression and protein levels for GADD45A, HSPA1B, PPP1R15A and WEE1. For GADD45A, the results of the western blot analyses corresponded to the gene expression changes in A-204 and VA-ES-BJ cells. Specifically, combination treatment with TRD and TRAIL caused increased protein expression compared to control and treatment with TRAIL (Fig. 7A). HSPA1B was upregulated in TRD-treated SK-LMS-1 and VA-ES-BJ cells corresponding to the results of the microarray and PCR analyses (Fig. 7B). Analogous to the 
Table II. Summary of the microarray and rtPCR data of the selected candidate genes.

\begin{tabular}{lccc}
\hline \multicolumn{3}{c}{ Signal log ratio control vs. TT } \\
$\begin{array}{l}\text { Gene symbol/ } \\
\text { cell line }\end{array}$ & GADD45A & PPP1R15A & HSPA1B \\
\hline $\begin{array}{l}\text { Microarray data } \\
\text { A-204 }\end{array}$ & 1.77 & 2.03 & 0.68 \\
SK-LMS-1 & 1.77 & 1.96 & 2.13 \\
VA-ES-BJ & 1.19 & 2.17 & 1.04 \\
rtPCR data & & & \\
A-204 & 2.05 & 1.81 & 0.82 \\
SK-LMS-1 & 1.74 & 1.36 & 1.69 \\
VA-ES-BJ & 1.89 & 2.24 & 1.57 \\
\hline
\end{tabular}

TT, TRD plus TRAIL.

gene expression levels, protein expression of PPP1R15A was enhanced by treatment with the different agents in all cell lines, in which combination treatment led to the highest protein levels (Fig. 7C). In all treated cell lines, Weel was downregulated in the microarray analyses and in the protein analyses after treatment with TRD (Fig. 7D).

\section{Discussion}

Since the discovery of TRAIL as a cell death-inducing member of the TNF-superfamily, its effects on apoptosis have been demonstrated for several malignancies, including soft tissue sarcomas $(46,47)$. In order to overcome TRAIL-resistance or enhance its apoptotic activity there is an increasing interest to find suitable combination partners for TRAIL (48-50). Recent trails unveiled the anti-neoplastic qualities of TRD $(31,36,38,51)$. In this study, we chose to combine TRAIL with TRD to treat three different soft tissue sarcoma cell lines. In our study the combination of TRAIL and TRD induced apoptotic cell death in A-204 rhabdomyosarcoma and VA-ES-BJ epithelioid sarcoma cells but not in SK-LMS-1 leiomyosarcoma cells. For both treated cell lines, the apoptotic index could be increased significantly by addition of TRAIL compared to treatment with TRD alone, suggesting that TRD and TRAIL work synergistically in rhabdomyosarcoma and epithelioid sarcoma cell lines beyond the mere additive effect. Earlier trials also revealed synergistic effects of TRAIL and the chemotherapeutic agent melphalan in the rhabdomyosarcoma cell line Te-671 (52). Likewise, the combined application of TRAIL and doxorubicin was shown to be more effective than single treatment of TRAIL in several rhabdomyosarcoma cell lines (53). To our knowledge, there are no trials evaluating TRAIL in epithelioid sarcomas. Merely paclitaxel and 5-FU are known to induce apoptosis in different epithelioid sarcoma cell lines (54).

TRD inhibited proliferation in all tested sarcoma cell lines. Strikingly, the anti-proliferative effect of TRD was enhanced significantly in SK-LMS-1 leiomyosarcoma cells by addition of TRAIL. Meanwhile, recent studies revealed TRD-induced proliferation inhibition in a wide range of malignant cell lines, including HT1080 human fibrosarcoma cells $(30,34,35,40)$. Remarkably, proliferation inhibition was accompanied by a disruption of cell adherence and cytoskeleton which play a crucial role in tumour growth, metastasis and development. However, the exact mechanism of TRD-induced proliferation inhibition is still unknown and the appealing hypothesis that TRD inhibits cell proliferation by disruption of cell adhesion and cytoskeleton requires further experimental support.

RNA-microarray technology showed high correlations between apoptotic efficacy and upregulation of GADD45A (growth arrest and DNA damage-inducible protein 45), PPP1R15A (protein phosphatase 1 regulatory subunit $15 \mathrm{~A}$, synonym: GADD34) and HSPA1B (heat shock $70 \mathrm{kDa}$ protein 1B).

GADD45A and PPP1R15A were upregulated with at least $\mathrm{a} \geq 2$-fold change in all three cell lines after single treatment with TRD and combined treatment with TRD and TRAIL compared to untreated control. Gene alteration could be confirmed by quantitative real-time PCR and western blot analysis.

GADD45 proteins co-operate in the activation of S and G2-M checkpoints following the exposure of cells to UV irradiation and other genotoxic stresses, thereby inducing growth arrest and apoptosis (55). The mechanisms by which GADD45 proteins function in negative growth control is not fully understood, although upregulation of these proteins was reported to be associated with increased apoptosis and p53-independent cell cycle arrest in a variety of soft tissue sarcomas (56). In a recent immunohistochemical study, high expression of GADD45 was associated with reduced invasiveness of chondrosarcomas, suggesting its potential diagnostic value in the histological grading of malignant chondrogenic tumours (57). However, the increased expression of GADD45B in our experiments suggests a potential involvement of GADD45B in TRD-mediated cell death in soft tissue sarcoma cells and has to be addressed in further studies.

Stressful growth conditions and exposure to DNA damaging agents lead to an upregulation of PPP1R15A in a wide range of human cell lines $(58,59)$. High expression of PPP1R15A is known to promote apoptotic cell death in a p53-independent manner (59-61). A recent in vitro study detected enhanced gene expression of PPP1R15A during TRD-induced cell death in different malignant cell lines including human fibrosarcoma cells (62). Thus, PPP1R15A should be considered as a potential target of TRD in cancer cells.

Combination treatment with TRAIL and TRD enhanced HSPA1B protein level in SK-LMS-1 leiomyosarcoma and VA-ES-BJ epithelioid cell sarcoma cells. HSPA1B protein belongs to the heat shock protein family with a molecular weight of $70 \mathrm{kDa}$ which acts as an important regulator of cell growth and survival in a wide range of cancer cells (63-65). These proteins are known to affect the intrinsic pathway by the inhibition of mitochondrial cytochrome $c$ release and also by preventing apoptosome assembly (29). Upregulation of heat-shock proteins in different malignant cell lines was associated with an enhanced resistance towards hypoxiainduced apoptosis (66). More particularly, heat-shock $70 \mathrm{kDa}$ proteins protected nucleus integrity in non-small cell lung carcinoma cells which were subjected to heat shock (67). In 
patients with urothelial carcinoma high levels of HSPA1B protein were associated with early tumour progression and invasion (68). Furthermore, recent in vitro studies suggested that heat-shock $70 \mathrm{kDa}$ proteins might be responsible for chemoresistance in different malignant cell lines, and increased levels were found in 5-fluorouracil-resistant colon carcinoma cells suggesting its involvement in colon cancer chemoresistance (69), whereas inhibition of heat shock $70 \mathrm{kDa}$ protein helped to overcome resistance to etoposide and 5-fluorouracil in oral squamous carcinoma cells (70). Moreover, TNF- and TRAIL-induced apoptosis could be suppressed by heat-shock $70 \mathrm{kDa}$ in many different cell types (71). We could not be sure which of the manifold effects of heat-shock proteins are relevant in sarcoma cell death. Their upregulation might only be a response to TRAIL- and TRD-induced cell stress. However, heat-shock proteins are essential to the survival of many cell types and might be one of the tools in chemoresistance in leiomyosarcoma or epithelioid cell sarcoma cells.

Microarray analysis revealed a decrease of FADD with $a \geq 2$-fold change in all three cell lines after combination treatment. FADD participates in death signalling in the extrinsic apoptotic pathway and can be recruited by several death receptors, including TRAIL-receptor. Subsequently this interaction leads to recruitment of caspase 8 and initiation of apoptosis. The role of FADD in TRAIL signalling is controversial (73). Some studies showed that the absence of FADD leads to partial TRAIL-resistance and concluded that FADD is necessary for TRAIL-induced apoptosis by the death receptors DR4 and DR5 (74,75). Other groups showed that the induction of apoptosis by TRAIL is independent of FADD in different cell lines $(73,76,77)$. Additionally, FADD was described as a negative regulator of the transcription factor $\mathrm{NF}-\kappa \mathrm{B}$ (nuclear factor $\kappa$-light chain-enhancer of activated B-cells), which promotes cell survival and tumour invasiveness of fibrosarcoma cells $(78,79)$. In our study, we observed consistent downregulation of FADD mRNA in all cell lines and protein levels in the SK-LMS-1 cells. Repetitive western blot analyses in A-204 and VA-ES-BJ did not show significant changes in protein expression. Therefore, a meaningful interpretion whether the downregulation of FADD plays a role in activation of apoptosis in the tested soft tissue sarcoma cells is not possible based on our data.

Expression of the PPM1D gene was downregulated with $a \geq 2$-fold change in all three sarcoma cell lines. PPM1D, also known as Wipl, is a member of the nuclear type $2 \mathrm{C}$ protein phosphatase family and is known to be a negative regulator of cell stress response pathways (80). Previous studies have shown that PPM1D expression and phosphatase activity are required for the survival and progression of breast and ovarian carcinoma cells (81-83). Loss of PPM1D gene function sensitises mouse embryonic fibroblasts to stress- and DNA damage-induced apoptosis (84). PPM1D overexpression has been observed in neuroblastomas, medulloblastomas, pancreatic adenocarcinomas and gastric carcinomas (85-89). Since there has been evidence that PPM1D acts as an oncogene, efforts were made to find selective inhibitors of PPM1D. As expected, tumour cell lines that overexpress PPM1D have shown to be more sensitive to PPM1D inhibition and consecutive apoptosis than cell lines with normal levels (90). These findings point to PPM1D as a regulator in tumour cell survival.

The cell cycle gene Weel was downregulated in all 3 cell lines after single treatment with TRD as well as combined treatment with TRD and TRAIL. Though PCR measurements were not performed to confirm gene expression, microarray analyses and western blot analyses results were consistent for all cell lines. The Weel protein kinase functions as key regulator of the $\mathrm{G} 2 / \mathrm{M}$-checkpoint and stabilizes the genome in the S phase (91). Overexpression of Wee1 has previously been reported in osteosarcoma, glioblastoma, breast cancer and malignant melanomas (92-95). Recent studies identified Wee1 as a potential molecular target in cancer cells and the selective small molecule Weel-inhibitor MK-1775 demonstrated promising results in cancer cells with enhanced levels of Weel (96-98). However, MK-1775 has recently been included in a phase I clinical trial in patients with advanced solid tumours $(95,99)$. In a present study, MK-1775 caused significantly apoptotic cell death in various sarcoma cell lines and patient-derived tumour explants ex vivo suggesting that Weel may represent a new potential target in the treatment of sarcomas (100).

Combined treatment with TRD and TRAIL led to an upregulation of the Fyn gene primarily in A-204 and VA-ES-BJ cells. Fyn belongs to the Src family of kinases and is involved in a variety of signalling pathways. It is particularly upregulated in prostate cancer cells and may have a pivotal role in cancer progression and metastasis (101). Furthermore, high levels of Fyn activity were correlated with a higher metastatic ability of human pancreatic carcinoma and murine fibrosarcoma cells $(102,103)$. However, these findings would indicate an enhanced cancer activity with subsequent disease aggravation induced by TRAIL and TRD and require further investigations.

Taken together, all results described above arose from in vitro tests. To make more concrete conclusions, further in vivo studies are necessary to specify programmed cell death following TRD and TRAIL treatment in soft tissue sarcomas and the results should be validated with primary cultures. Finally, gene expression and cell viability differed remarkably in all three analysed sarcoma entities after exposure to TRD and TRAIL pointing out the pivotal cellular differences among the soft tissue sarcoma subtypes. Unfortunately, most of the large clinical trials did not differentiate between histological subtypes because of the overall rarity of soft tissue sarcomas resulting in generalized pharmaceutical references and therapy. However, our findings sustain the approach of individualized therapy and investigation. Future trials as well as clinical therapy should focus on histological subtypes and be more indivualized in spite of the rarity and difficulties.

\section{Acknowledgements}

The authors thank Professor W. E. Schmidt (Department of Medicine I, St. Josef Hospital, Ruhr University of Bochum) and Professor A. Muegge (Department of Medicine II, St. Josef Hospital, Ruhr University of Bochum) for generously supporting our studies. Furthermore, they thank Annegret Flier, Ilka Werner, Kirsten Mros and Rainer Lebert for technical assistance. This study was supported by FoRUM Project F544 E-2007, Ruhr University Bochum, Germany. 


\section{References}

1. Hoos A, Lewis JJ and Brennan MF: Soft tissue sarcoma: prognostic factors and multimodal treatment. Chirurg 71: 787-794, 2000 (In German).

2. Patrikidou A, Domont J, Cioffi A and Le Cesne A: Treating soft tissue sarcomas with adjuvant chemotherapy. Curr Treat Options Oncol 12: 21-31, 2011.

3. Kaushal A and Citrin D: The role of radiation therapy in the management of sarcomas. Surg Clin North Am 88: 629-646, 2008.

4. O'Brien GC, Cahill RA, Bouchier-Hayes DJ and Redmond HP: Co-immunotherapy with interleukin-2 and taurolidine for progressive metastatic melanoma. Ir J Med Sci 175: 10-14, 2006.

5. Solomon LR, Cheesbrough JS, Bhargava R, et al: Observational study of need for thrombolytic therapy and incidence of bacteremia using taurolidine-citrate-heparin, taurolidine-citrate and heparin catheter locks in patients treated with hemodialysis. Semin Dial 25: 233-238, 2012.

6. Karavasilis V, Seddon BM, Ashley S, Al-Muderis O, Fisher C and Judson I: Significant clinical benefit of first-line palliative chemotherapy in advanced soft-tissue sarcoma: retrospective analysis and identification of prognostic factors in 488 patients. Cancer 112: 1585-1591, 2008.

7. Billingsley KG, Lewis JJ, Leung DH, Casper ES, Woodruff JM and Brennan MF: Multifactorial analysis of the survival of patients with distant metastasis arising from primary extremity sarcoma. Cancer 85: 389-395, 1999.

8. Pezzi CM, Pollock RE, Evans HL, et al: Preoperative chemotherapy for soft-tissue sarcomas of the extremities. Ann Surg 211: 476-481, 1990

9. Donato Di Paola E and Nielsen OS: The EORTC soft tissue and bone sarcoma group. European Organisation for Research and Treatment of Cancer. Eur J Cancer 38 (Suppl 4): S138-S141, 2002

10. Nedea EA and DeLaney TF: Sarcoma and skin radiation oncology. Hematol Oncol Clin North Am 20: 401-429, 2006.

11. Brodowicz T, Schwameis E, Widder J, et al: Intensified adjuvant IFADIC chemotherapy for adult soft tissue sarcoma: a prospective randomized feasibility trial. Sarcoma 4: 151-160, 2000.

12. Frustaci S, Gherlinzoni F, De Paoli A, et al: Adjuvant chemotherapy for adult soft tissue sarcomas of the extremities and girdles: results of the Italian randomized cooperative trial. J Clin Oncol 19: 1238-1247, 2001.

13. Bramwell V, Rouesse J, Steward W, et al: Adjuvant CYVADIC chemotherapy for adult soft tissue sarcoma - reduced local recurrence but no improvement in survival: a study of the European Organization for Research and Treatment of Cancer Soft Tissue and Bone Sarcoma Group. J Clin Oncol 12: 1137-1149, 1994.

14. Sarcoma Meta-analysis Collaboration: Adjuvant chemotherapy for localised resectable soft-tissue sarcoma of adults: metaanalysis of individual data. Lancet 350: 1647-1654, 1997.

15. Hirata $\mathrm{T}$, Yonemori $\mathrm{K}$, Ando $\mathrm{M}$, et al: Efficacy of taxane regimens in patients with metastatic angiosarcoma. Eur J Dermatol 21: 539-545, 2011.

16. Penel N, Van Glabbeke M, Marreaud S, Ouali M, Blay JY and Hohenberger P: Testing new regimens in patients with advanced soft tissue sarcoma: analysis of publications from the last 10 years. Ann Oncol 22: 1266-1272, 2011.

17. Mentzel T: Epithelioid sarcoma: morphologic variants and differential diagnosis. Pathologe 31: 135-141, 2010

18. Chromik AM, Daigeler A, Bulut D, et al: Comparative analysis of cell death induction by Taurolidine in different malignant human cancer cell lines. J Exp Clin Cancer Res 29: 21, 2010.

19. Chromik AM, Daigeler A, Hilgert C, et al: Synergistic effects in apoptosis induction by taurolidine and TRAIL in HCT-15 colon carcinoma cells. J Invest Surg 20: 339-348, 2007.

20. Daigeler A, Chromik AM, Geisler A, et al: Synergistic apoptotic effects of taurolidine and TRAIL on squamous carcinoma cells of the esophagus. Int J Oncol 32: 1205-1220, 2008.

21. Daigeler A, Chromik AM, Haendschke K, et al: Synergistic effects of sonoporation and taurolidin/TRAIL on apoptosis in human fibrosarcoma. Ultrasound Med Biol 36: 1893-1906, 2010.

22. Yagita H, Takeda K, Hayakawa Y, Smyth MJ and Okumura K: TRAIL and its receptors as targets for cancer therapy. Cancer Sci 95: 777-783, 2004.

23. Bouralexis S, Findlay DM and Evdokiou A: Death to the bad guys: targeting cancer via Apo2L/TRAIL. Apoptosis 10: 35-51, 2005 .
24. Rowinsky EK: Targeted induction of apoptosis in cancer management: the emerging role of tumor necrosis factor-related apoptosis-inducing ligand receptor activating agents. J Clin Oncol 23: 9394-9407, 2005.

25. Ashkenazi A, Pai RC, Fong S, et al: Safety and antitumor activity of recombinant soluble Apo2 ligand. J Clin Invest 104: 155-162, 1999.

26. Ganten D, Ruckpaul K and Daniel P: Molekulare Grundlagen der Apoptose. In: Grundlagen der Molekularen Medizin. Springer Berlin, Heidelberg, pp159-203, 2008.

27. Newsom-Davis T, Prieske S and Walczak H: Is TRAIL the holy grail of cancer therapy? Apoptosis 14: 607-623, 2009.

28. LeBlanc HN and Ashkenazi A: Apo2L/TRAIL and its death and decoy receptors. Cell Death Differ 10: 66-75, 2003.

29. Beere HM: Death versus survival: functional interaction between the apoptotic and stress-inducible heat shock protein pathways. J Clin Invest 115: 2633-2639, 2005.

30. Jacobi CA, Menenakos C and Braumann C: Taurolidine - a new drug with anti-tumor and anti-angiogenic effects. Anticancer Drugs 16: 917-921, 2005.

31. McCourt M, Wang JH, Sookhai S and Redmond HP: Taurolidine inhibits tumor cell growth in vitro and in vivo. Ann Surg Oncol 7: 685-691, 2000

32. Petrovic L, Schlegel KA, Ries J, et al: In vitro effect of taurolidine on squamous cell carcinoma in the oral cavity. Mund Kiefer Gesichtschir 7: 102-107, 2003 (In German).

33. Gallagher KA, Liu ZJ, Xiao M, et al: Diabetic impairments in NO-mediated endothelial progenitor cell mobilization and homing are reversed by hyperoxia and SDF-1 alpha. J Clin Invest 117: 1249-1259, 2007.

34. Calabresi P, Goulette FA and Darnowski JW: Taurolidine: cytotoxic and mechanistic evaluation of a novel antineoplastic agent. Cancer Res 61: 6816-6821, 2001.

35. Braumann C, Henke W, Jacobi CA and Dubiel W: The tumorsuppressive reagent taurolidine is an inhibitor of protein biosynthesis. Int J Cancer 112: 225-230, 2004.

36. Neary PM, Hallihan P, Wang JH, Pfirrmann RW, BouchierHayes DJ and Redmond HP: The evolving role of taurolidine in cancer therapy. Ann Surg Oncol 17: 1135-1143, 2010.

37. Darnowski JW, Goulette FA, Cousens LP, Chatterjee D and Calabresi P: Mechanistic and antineoplastic evaluation of taurolidine in the DU145 model of human prostate cancer. Cancer Chemother Pharmacol 54: 249-258, 2004.

38. Stendel R, Biefer HR, Dekany GM, et al: The antibacterial substance taurolidine exhibits anti-neoplastic action based on a mixed type of programmed cell death. Autophagy 5: 194-210, 2009.

39. Stendel R, Scheurer L, Stoltenburg-Didinger G, Brock M and Mohler H: Enhancement of Fas-ligand-mediated programmed cell death by taurolidine. Anticancer Res 23: 2309-2314, 2003.

40. Daigeler A, Brenzel C, Bulut D, et al: TRAIL and Taurolidine induce apoptosis and decrease proliferation in human fibrosarcoma. J Exp Clin Cancer Res 27: 82, 2008.

41. Han Z, Ribbizi I, Pantazis P, Wyche J, Darnowski J and Calabresi P: The antibacterial drug taurolidine induces apoptosis by a mitochondrial cytochrome c-dependent mechanism. Anticancer Res 22: 1959-1964, 2002.

42. Braumann C, Winkler G, Rogalla P, Menenakos C and Jacobi CA: Prevention of disease progression in a patient with a gastric cancer-re-recurrence. Outcome after intravenous treatment with the novel antineoplastic agent taurolidine. Report of a case. World J Surg Oncol 4: 34, 2006.

43. Imhof L, Goldinger SM, Baumann K, et al: The antibacterial substance, taurolidine in the second/third-line treatment of very advanced stage IV melanoma including brain metastases: results of a phase 2, open-label study. Melanoma Res: Nov 3 , 2010 (Epub ahead of print).

44. Stendel R, Picht T, Schilling A, et al: Treatment of glioblastoma with intravenous taurolidine. First clinical experience. Anticancer Res 24: 1143-1147, 2004.

45. Backes C, Keller A, Kuentzer J, et al: GeneTrail - advanced gene set enrichment analysis. Nucleic Acids Res 35: W186-W192, 2007.

46. Pitti RM, Marsters SA, Ruppert S, Donahue CJ, Moore A and Ashkenazi A: Induction of apoptosis by Apo-2 ligand, a new member of the tumor necrosis factor cytokine family. J Biol Chem 271: 12687-12690, 1996.

47. Wiley SR, Schooley K, Smolak PJ, et al: Identification and characterization of a new member of the TNF family that induces apoptosis. Immunity 3: 673-682, 1995. 
48. Tomek S, Koestler W, Horak P, et al: Trail-induced apoptosis and interaction with cytotoxic agents in soft tissue sarcoma cell lines. Eur J Cancer 39: 1318-1329, 2003.

49. Clayer M, Bouralexis S, Evdokiou A, Hay S, Atkins GJ and Findlay DM: Enhanced apoptosis of soft tissue sarcoma cells with chemotherapy: A potential new approach using TRAIL. J Orthop Surg (Hong Kong) 9: 19-22, 2001.

50. Kondo K, Yamasaki S, Inoue N, et al: Prospective antitumor effects of the combination of tumor necrosis factor-related apoptosis-inducing ligand (TRAIL) and cisplatin against esophageal squamous cell carcinoma. Surg Today 36: 966-974, 2006.

51. Walters DK, Muff R, Langsam B, Gruber P, Born W and Fuchs B: Taurolidine: a novel anti-neoplastic agent induces apoptosis of osteosarcoma cell lines. Invest New Drugs 25: 305-312, 2007

52. Kluttermann K, Banning U, Kachel M, Krause C, Korholz D and Mauz-Korholz C: TRAIL-induced cytotoxicity in a melphalan-resistant rhabdomyosarcoma cell line via activation of caspase-2. Anticancer Res 26: 351-356, 2006.

53. Komdeur R, Meijer C, Van Zweeden M, et al: Doxorubicin potentiates TRAIL cytotoxicity and apoptosis and can overcome TRAIL-resistance in rhabdomyosarcoma cells. Int J Oncol 25: 677-684, 2004.

54. Heikaus S, Matuszek KS, Suschek CV, et al: Paclitaxel (Taxol)induced apoptosis in human epithelioid sarcoma cell lines is enhanced by upregulation of CD95 ligand (FasL/Apo-1L) J Cancer Res Clin Oncol 134: 689-695, 2008.

55. Gheorghescu B, Gherman I, Jovin GH, et al: Absorption studies in patients with parasitic infestation of the small intestine, before and after treatment. Med Interne 14: 31-38, 1976.

56. Nedeau AE, Gallagher KA, Liu ZJ and Velazquez OC: Elevation of hemopexin-like fragment of matrix metalloproteinase-2 tissue levels inhibits ischemic wound healing and angiogenesis. J Vasc Surg 54: 1430-1438, 2011.

57. Nedea ME, Vasilescu F, Gheorghescu B, Pavelescu E and Runcan V: Determination with thin layer chromatography of the distribution of lipids in the feces and study of the incorporation of certain C 14 -labeled 1-fatty acids into the different lipid fractions. Fiziol Norm Patol 19: 67-73, 1973 (In Romanian)

58. Hollander MC, Poola-Kella S and Fornace AJ: Gadd34 functional domains involved in growth suppression and apoptosis. Oncogene 22: 3827-3832, 2003.

59. Hollander MC, Zhan Q, Bae I and Fornace AJ Jr: Mammalian GADD34, an apoptosis- and DNA damage-inducible gene. J Biol Chem 272: 13731-13737, 1997.

60. Adler HT, Chinery R, Wu DY, et al: Leukemic HRX fusion proteins inhibit GADD34-induced apoptosis and associate with the GADD34 and hSNF5/INI1 proteins. Mol Cell Biol 19: 7050-7060, 1999.

61. Grishin AV, Azhipa O, Semenov I and Corey SJ: Interaction between growth arrest-DNA damage protein 34 and Src kinase Lyn negatively regulates genotoxic apoptosis. Proc Natl Acad Sci USA 98: 10172-10177, 2001.

62. Chromik AM, Hahn SA, Daigeler A, et al: Gene expression analysis of cell death induction by taurolidine in different malignant cell lines. BMC Cancer 10: 595, 2010.

63. Rohde M, Daugaard M, Jensen MH, Helin K, Nylandsted J and Jaattela M: Members of the heat-shock protein 70 family promote cancer cell growth by distinct mechanisms. Genes Dev 19: 570-582, 2005

64. Daugaard M, Rohde M and Jaattela M: The heat shock protein 70 family: highly homologous proteins with overlapping and distinct functions. FEBS Lett 581: 3702-3710, 2007.

65. Noguchi T, Takeno S, Shibata T, Uchida Y, Yokoyama S and Muller W: Expression of heat shock protein 70 in grossly resected esophageal squamous cell carcinoma. Ann Thorac Surg 74: 222-226, 2002.

66. Huang WJ, Xia LM, Zhu F, et al: Transcriptional upregulation of HSP70-2 by HIF-1 in cancer cells in response to hypoxia. Int J Cancer 124: 298-305, 2009.

67. Scieglinska D, Piglowski W, Mazurek A, et al: The HspA2 protein localizes in nucleoli and centrosomes of heat shocked cancer cells. J Cell Biochem 104: 2193-2206, 2008.

68. Garg M, Kanojia D, Seth A, et al: Heat-shock protein 70-2 (HSP70-2) expression in bladder urothelial carcinoma is associated with tumour progression and promotes migration and invasion. Eur J Cancer 46: 207-215, 2010.

69. Grivicich I, Regner A, Zanoni C, et al: Hsp70 response to 5 -fluorouracil treatment in human colon cancer cell lines. Int J Colorectal Dis 22: 1201-1208, 2007.
70. Park SR, Lee KD, Kim UK, et al: Pseudomonas aeruginosa exotoxin A reduces chemoresistance of oral squamous carcinoma cell via inhibition of heat shock proteins 70 (HSP70). Yonsei Med J 51: 708-716, 2010.

71. Beere HM: 'The stress of dying': the role of heat shock proteins in the regulation of apoptosis. J Cell Sci 117: 2641-2651, 2004.

72. Valoti G, Nicoletti MI, Pellegrino A, et al: Ecteinascidin-743, a new marine natural product with potent antitumor activity on human ovarian carcinoma xenografts. Clin Cancer Res 4: 1977-1983, 1998.

73. Zhang L and Fang B: Mechanisms of resistance to TRAILinduced apoptosis in cancer. Cancer Gene Ther 12: 228-237, 2005.

74. Kuang AA, Diehl GE, Zhang $\mathrm{J}$ and Winoto A: FADD is required for DR4- and DR5-mediated apoptosis: lack of trail-induced apoptosis in FADD-deficient mouse embryonic fibroblasts. J Biol Chem 275: 25065-25068, 2000.

75. Bodmer JL, Holler N, Reynard S, et al: TRAIL receptor-2 signals apoptosis through FADD and caspase-8. Nat Cell Biol 2: 241-243, 2000

76. Petak I, Vernes R, Szucs KS, et al: A caspase-8-independent component in TRAIL/Apo-2L-induced cell death in human rhabdomyosarcoma cells. Cell Death Differ 10: 729-739, 2003.

77. Piras V, Hayashi K, Tomita M and Selvarajoo K: Enhancing apoptosis in TRAIL-resistant cancer cells using fundamental response rules. Sci Rep 1: 144, 2011

78. Duckett CS: Apoptosis and NF-kappa B: the FADD connection. J Clin Invest 109: 579-580, 2002

79. Park JM, Kim A, Oh JH and Chung AS: Methylseleninic acid inhibits PMA-stimulated pro-MMP-2 activation mediated by MT1-MMP expression and further tumor invasion through suppression of NF-kappaB activation. Carcinogenesis 28: 837-847, 2007.

80. Fiscella M, Zhang H, Fan S, et al: Wip1, a novel human protein phosphatase that is induced in response to ionizing radiation in a p53-dependent manner. Proc Natl Acad Sci USA 94: 6048-6053, 1997.

81. Lambros MB, Natrajan R, Geyer FC, et al: PPM1D gene amplification and overexpression in breast cancer: a qRT-PCR and chromogenic in situ hybridization study. Mod Pathol 23: $1334-1345,2010$.

82. Natrajan R, Lambros MB, Rodriguez-Pinilla SM, et al: Tiling path genomic profiling of grade 3 invasive ductal breast cancers. Clin Cancer Res 15: 2711-2722, 2009.

83. Tan DS, Lambros MB, Rayter S, et al: PPM1D is a potential therapeutic target in ovarian clear cell carcinomas. Clin Cancer Res 15: 2269-2280, 2009.

84. Xia Y, Ongusaha P, Lee SW and Liou Y-C: Loss of Wip1 sensitizes cells to stress- and DNA damage-induced apoptosis. J Biol Chem 284: 17428-17437, 2009.

85. Saito-Ohara F, Imoto I, Inoue J, et al: PPM1D is a potential target for 17q gain in neuroblastoma. Cancer Res 63: 1876-1883, 2003.

86. Loukopoulos P, Shibata T, Katoh H, et al: Genome-wide array-based comparative genomic hybridization analysis of pancreatic adenocarcinoma: identification of genetic indicators that predict patient outcome. Cancer Sci 98: 392-400, 2007.

87. Fuku T, Semba S, Yutori H and Yokozaki H: Increased wild-type p53-induced phosphatase 1 (Wip1 or PPM1D) expression correlated with downregulation of checkpoint kinase 2 in human gastric carcinoma. Pathol Int 57: 566-571, 2007.

88. Castellino RC, De Bortoli M, Lu X, et al: Medulloblastomas overexpress the p53-inactivating oncogene WIP1/PPM1D. J Neurooncol 86: 245-256, 2008.

89. Lu X, Nguyen TA, Moon SH, Darlington Y, Sommer M and Donehower LA: The type 2C phosphatase Wipl: an oncogenic regulator of tumor suppressor and DNA damage response pathways. Cancer Metastasis Rev 27: 123-135, 2008.

90. Rayter S, Elliott R, Travers J, et al: A chemical inhibitor of PPM1D that selectively kills cells overexpressing PPM1D. Oncogene 27: 1036-1044, 2008.

91. Sorensen CS and Syljuasen RG: Safeguarding genome integrity: the checkpoint kinases ATR, CHK1 and WEE1 restrain CDK activity during normal DNA replication. Nucleic Acids Res 40: 477-486, 2012 .

92. Mir SE, De Witt Hamer PC, Krawczyk PM, et al: In silico analysis of kinase expression identifies WEE1 as a gatekeeper against mitotic catastrophe in glioblastoma. Cancer Cell 18: 244-257, 2010.

93. Iorns E, Lord CJ, Grigoriadis A, et al: Integrated functional, gene expression and genomic analysis for the identification of cancer targets. PloS One 4: e5120, 2009. 
94. Posthuma DeBoer J, Wurdinger T, Graat HC, et al: WEE1 inhibition sensitizes osteosarcoma to radiotherapy. BMC Cancer 11: 156, 2011.

95. Magnussen GI, Holm R, Emilsen E, Rosnes AK, Slipicevic A and Florenes VA: High expression of weel is associated with poor disease-free survival in malignant melanoma: potential for targeted therapy. PloS One 7: e38254, 2012.

96. Hirai H, Iwasawa Y, Okada M, et al: Small-molecule inhibition of Weel kinase by MK-1775 selectively sensitizes p53-deficient tumor cells to DNA-damaging agents. Mol Cancer Ther 8: 2992-3000, 2009.

97. Rajeshkumar NV, De Oliveira E, Ottenhof N, et al: MK-1775, a potent Weel inhibitor, synergizes with gemcitabine to achieve tumor regressions, selectively in p53-deficient pancreatic cancer xenografts. Clin Cancer Res 17: 2799-2806, 2011.

98. Bridges KA, Hirai H, Buser CA, et al: MK-1775, a novel Wee1 kinase inhibitor, radiosensitizes p53-defective human tumor cells. Clin Cancer Res 17: 5638-5648, 2011.
99. Hirai H, Arai T, Okada M, et al: MK-1775, a small molecule Wee1 inhibitor, enhances anti-tumor efficacy of various DNA-damaging agents, including 5-fluorouracil. Cancer Biol Ther 9: 514-522, 2010.

100. Kreahling JM, Gemmer JY, Reed D, Letson D, Bui M and Altiok S: MK1775, a selective Weel inhibitor, shows singleagent antitumor activity against sarcoma cells. Mol Cancer Ther 11: 174-182, 2012.

101. Saito YD, Jensen AR, Salgia R and Posadas EM: Fyn: a novel molecular target in cancer. Cancer 116: 1629-1637, 2010.

102. Chen Z-Y, Cai L, Bie P, et al: Roles of Fyn in pancreatic cancer metastasis. J Gastroenterol Hepatol 25: 293-301, 2010.

103. Koike K, Kogawa K, Takayama T, et al: Enhanced expression of type IV collagen-binding protein (p29) in Fyn-transfected murine fibrosarcoma cells. Jpn J Cancer Res 93: 1090-1099, 2002. 